\title{
NEUROLOGICAL RECOVERY AND FUNCTIONAL OUTCOME OF COMPLETE TRAUMATIC SPINAL CORD INJURY PATIENTS: AN OBSERVATION FROM BANGLADESH
}

Kamrunnaher ${ }^{1}$, Sayeed Uddin Helal ${ }^{2}$, Palash Chandra Saha ${ }^{3}$, Farzana Taoheed ${ }^{4}$ S.M. Yasir Arafat ${ }^{5}$, Md. Akhlasur Rahman ${ }^{6}$, Md. Shahoriar Ahmed *7.

1,3 BOT, Centre for the Rehabilitation of the Paralysed, Bangladesh.

${ }^{2}$ Consultant Neurosurgeon \& Head of Medical Services Wing, Centre for the rehabilitation of the Paralysed (CRP).

${ }^{5}$ MBBS, MBA, MPH, MD Resident, Department of Psychiatry, Bangabandhu Sheikh Mujib Medical University, Bangladesh.

${ }^{4,6}$ BPT, Centre for the Rehabilitation of the Paralysed (CRP), Bangladesh.

${ }^{*} \mathrm{MPH}$, Executive Officer, Bangladesh Physiotherapy Association (BPA).

\section{ABSTRACT}

Background: Neurological recovery and functional outcome is the burning issue for the spinal cord injury patients where neurological recovery depends on the improvement of motor score and ASIA impairment scale.

Objective: It was aimed to explore the neurological recovery and functional outcome of complete traumatic spinal cord injury patients in a rehabilitation center of Bangladesh.

Materials and Methods: Data were collected retrospectively from the record of $437 \mathrm{SCl}$ patients from June 2014 to June 2017.. We collect initial neurologic deficit, ASIA, SCIM and demographic data at admission and neurological deficit ASIA and SCIM after three months to compare of their neurological extent as well as functional outcome.

Results: Majority of the participants had traumatic paraplegia $(63.6 \%)$ and the principle cause was fall from height (51.3\%). 26 (5.9\%) of the patients were shifted into B from AIS A, 38 (8.7\%) were shifted into C, 28 (6.4\%) were shifted into D. Among 437 participants three hundred and thirty-eight (77.3\%) were wheelchair-dependent and forty-nine (11.2\%) were walking at the time of discharge.

Conclusion: Though neurological and functional recovery is rare for the complete $\mathrm{SCl}$, but the study has shown us a hopeful aspiration. Further research on a larger scale studies is necessary to generalize the result.

KEY WORDS: Neurological recovery, Functional outcome, Complete SCI, CRP, Bangladesh.

Address for correspondence: Dr. Md. Shahoriar Ahmed, MPH, Executive Officer, Bangladesh Physiotherapy Association (BPA). Cell No: +8801794859401, E-Mail: physio.shahoriar@gmail.com

Access this Article online

Quick Response code

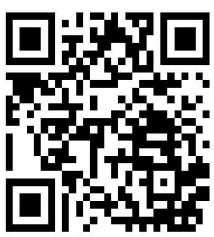

DOI: $10.16965 /$ ijpr.2018.106

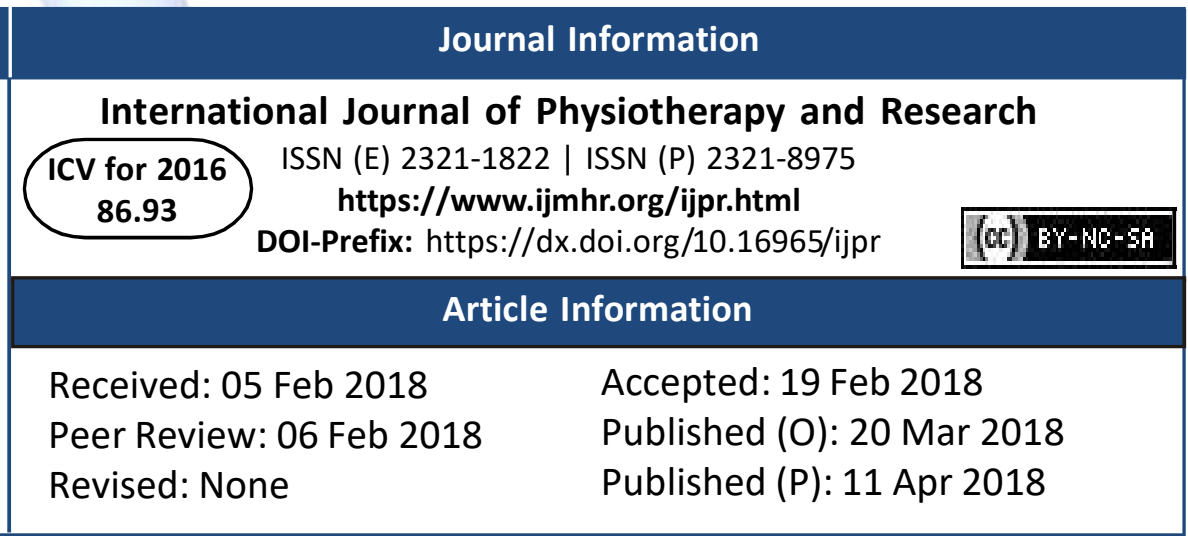

\section{INTRODUCTION}

Spinal cord injury $(\mathrm{SCl})$ is a sudden debilitating and devastating $[1,2,3]$ event that causes longterm disability, increases morbidity and mortality [4]. SCl could be traumatic or non-traumatic
[2] and the extent of it cause upper and lower motor loss as well as sensory impairments, which are turn into complete or an incomplete lesion [5]. SCl mostly occurs in mid 20s and worldwide approximate annual incidence is 22 
per million of population [6].

Neurological recovery and functional outcome is the burning issue for the $\mathrm{SCl}$ patients. Most of the $\mathrm{SCl}$ patients after injury want to know when he/she can able to walk. Sometimes this is a prime goal of $\mathrm{SCl}$ patients throughout of his/ her course of the treatment $[5,7]$. But neurological recovery depends on the improvement of motor scores and American Spinal Injury Association (ASIA) impairment scale [8].

Less severe damaged cord which is known as incomplete and classified as American Spinal Injury Association Impairment Scale (AIS)-B, C, $D$ has shown different extent of neurological and functional improvement. Whereas severely damaged cord which is classified as AIS-A, has rare possibility of having neurological improvement. Previously it was thought that a complete case will never become incomplete one. Fortunately now a day some of the studies showed the remarkable sensory-motor improvement even for the complete injured patients who never underwent surgery. An evident showed $12.1 \%$ of complete $A$ converted to AIS grade $B$ and $77.2 \%$ improved to AIS grade D whose Initial AIS was $C$ approximately after 74 days [9].

Another study found that $2 \%$ to $3 \%$ complete $\mathrm{SCl}$ recovering to ASIA grade D status within 1 year after injury [10]. As functional outcome depends on neurological status or level of injury, neurological status or level of injury and natural recovery is very important for the measurement of prognosis and making management plan of a $\mathrm{SCl}$ patient [11]. Bangladeshis a developing country of South-Asia region, despite being burdened with 160 million populations has immense progress in health sector $[1,2]$. The aim of our study was to evaluate the amount of neurologic recovery and functional outcome in patients with complete traumatic spinal cord lesions. To the authors' best knowledge this is the first study to dealing with the neurological recovery and functional outcome of complete traumatic spinal cord injury patients in Bangladesh.

\section{METHODOLOGY}

Ethical consideration: The researchers were duly concern regarding the ethical aspects of the study, the study received ethical approval
Rehabilitation of the Paralysed (CRP), Savar, Bangladesh. And which was conducted in accordance with the Declaration of Helsinki. All information was kept in secure. Confidentiality of the person and the information was maintained and observed and unauthorized persons did not have any access to the collected data.

Study Design: After clearance from Institutional Ethics Committee, we conducted a retrospective analysis of AIS grade, sensory level, SCIMS and demography related data. We included 437 $\mathrm{SCl}$ patients who were admitted to the Centre for the Rehabilitation of the Paralysed (CRP). Study shows that 72-hour to 1 -week examination most commonly used for long-term neurologic outcomes [12]. So During admission an initial neurologic deficit was assessed according to the ASIA standards [13] done by medical professionals with evaluation of right and left motor and sensory levels and ASIA impairment scale, and after completion of at least three months rehabilitation program during discharge time again ASIA done by well-trained medical professionals as because of compare of their Neurological extent as well as Functional outcome. Patient assessed according to ASIA impairment scale classes $A, B, C$ and $D$ [8]. After then motor score and Spinal Cord Independence Measure (SCIM) [14] changes were calculated based on the difference between admission and discharge during rehabilitation time. Since 1990 CRP provide three months rehabilitation program which was a complete predefined preplanned Rehabilitation program for $\mathrm{SCl}$ patients. This three month Rehabilitation program is performed by multi-disciplinary medical professionals, but some cases this time might be increase according to patient improvement and secondary complication.

Site: CRP is a well-known not for profit organization in Bangladesh for Rehabilitation of the $\mathrm{SCl}$ patients. As a mother organization CRP receives referrals from different hospitals and from all over the Bangladesh for Rehabilitation of the $\mathrm{SCl}$ patients. CRP provides acute care for $\mathrm{SCl}$ patients and admits approximately $388 \mathrm{SCl}$ patients in each year [15] which makes this NGO (Non-Government Organization) one of the largest acute spinal cord injury units in South East Asia. 
Participants Data were collected retrospectively from hospital records from June 2014 to June 2017. We include all AIS complete $A$, patients admitted to the CRP in the mentioned time. We exclude those participants who were below 15 years $[11,9]$ as because motor score may be varied or reduced in this subject. This research ensures all potential participants from hospital records.

Data collection and management: $\mathrm{SCl}$ participants, who completed their rehabilitation program from "June 2014 to June 2017", were collected from the medical records of the CRP hospital. Data that were recorded consisted of age, gender, cause of injury, neurological level of injury, methods of management, Neurological status at during and discharge from hospital. Neurological level and extent of injury were defined using the international standards set forth by the ASIA. Recovery was categorized as complete, incomplete.

Analysis: After managing data properly, it was analyzed in SPSS (Statistical Package of Social Science) 20 version and Microsoft Excel Software 2007 version.

\section{RESULT}

Table 1: Distribution of demographic variables of the respondents $(n=437)$.

\begin{tabular}{|c|c|c|}
\hline Demographic Variable & Frequency & Percentage \\
\hline \multicolumn{3}{|c|}{ Age } \\
\hline $15-24$ & 119 & 27.2 \\
\hline $25-34$ & 128 & 29.3 \\
\hline $35-44$ & 95 & 21.7 \\
\hline $45-54$ & 67 & 15.3 \\
\hline $55-64$ & 22 & 5 \\
\hline $65-74$ & 5 & 1.1 \\
\hline $75-84$ & 1 & 0.2 \\
\hline \multicolumn{3}{|c|}{ Gender } \\
\hline Male & 394 & 90.2 \\
\hline Female & 43 & 9.8 \\
\hline \multicolumn{3}{|c|}{ Educational level } \\
\hline Illiterate & 33 & 7.6 \\
\hline Signature only & 118 & 27 \\
\hline Primary & 180 & 41.2 \\
\hline SSC & 57 & 13 \\
\hline $\mathrm{HSC}$ & 38 & 8.7 \\
\hline Graduate & 11 & 2.5 \\
\hline \multicolumn{3}{|c|}{ Habitat } \\
\hline Rural & 304 & 69.6 \\
\hline Urban & 133 & 30.4 \\
\hline \multicolumn{3}{|c|}{ Occupation } \\
\hline Farmer & 83 & 19 \\
\hline Day labor & 133 & 30.4 \\
\hline Service holder & 65 & 14.9 \\
\hline Student & 62 & 14.2 \\
\hline House wife & 28 & 6.4 \\
\hline Businessman & 40 & 9.2 \\
\hline Driver & 19 & 4.3 \\
\hline Garments Worker & 7 & 1.6 \\
\hline
\end{tabular}

Among 437 respondents 394 were male (90.2\%) and 43 were female (9.8\%). Most of the patients were in their 3rd decade which consisted $29.3 \%$, followed by $27.2 \%$ in between $15-24$ years and $21.7 \%$ in between $35-44.304$ of the respondent (69.6\%) were from rural area and 133 were from urban area (30.4\%). Most of the participants were completed primary level of education 180 (41.2\%) and signature only 118 (27\%). Majority of the participants were Day laborer 133 (30.4\%), Farmer 83 (19\%), service holder 65 (14.9\%), student 62 (14.2\%) (Table 1).

Fig. 1: Cause of injury among the respondents.

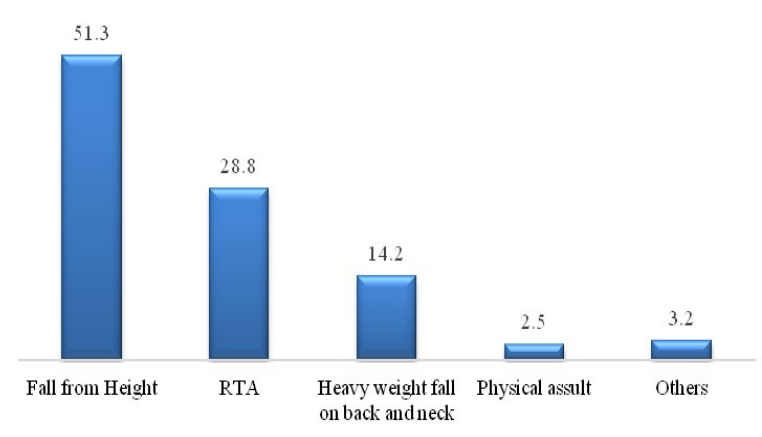

Most of the participants two hundred twenty four (51.3\%) had fall from height and Road traffic accident was the second most common cause having the distribution of one hundred twenty six patients (28.8\%). Sixty two patients (14.2\%) gave history of fall of Heavy weight over neck or back. Among other causes (3.2\%) diving into shallow water seven (1.6\%), Scarf injury three (.7\%) and Bull attack two (.5\%) were interesting cause of spinal cord injury patients (Figure 1).

Table 2: Characteristics of participants ( $n=437)$.

\begin{tabular}{|c|c|c|c|}
\hline & $\begin{array}{c}\text { All participants } \\
(\mathrm{n}=437)\end{array}$ & $\begin{array}{c}\text { Wheelchair on } \\
\text { discharge (n=388) }\end{array}$ & $\begin{array}{c}\text { Walking on } \\
\text { discharge (n=49) }\end{array}$ \\
\hline Gender & & & \\
\hline Male & $394(90.2)$ & $346(79.2)$ & $48(10.9)$ \\
\hline Female & $43(9.8)$ & $36(8.2)$ & $7(1.6)$ \\
\hline $\begin{array}{c}\text { Als Classification during } \\
\text { discharge, } \mathrm{n}^{\mathrm{a}}\end{array}$ & & & \\
\hline A & $344(78.7)$ & $332(85.8)$ & $12(24.5)$ \\
\hline B & $26(5.9)$ & $23(6)$ & $3(6.1)$ \\
\hline C & $38(8.7)$ & $28(7.2)$ & $10(20.4)$ \\
\hline D & $28(6.4)$ & $4(1.0)$ & $24(49)$ \\
\hline Type of injury & & & \\
\hline Traumatic tetraplegia (TT) & $159(36.4)$ & $139(35.8)$ & $20(40.8)$ \\
\hline Traumatic paraplegia (TP) & $278(63.6)$ & $249(64.2)$ & $29(59.2)$ \\
\hline
\end{tabular}

Abbreviations: AIS, American Spinal Injuries Association Impairment Scale; IQR, interquartile range.

${ }^{a}$ The AIS classification was missing for one person who was wheelchair user at discharge. 
The characteristics of the participants include from June 2014 to June 2017 are shown in Table 2. Three hundred and ninety-four $(90.2 \%)$ participants were male with a median (IQR) age of 30 years (17). All the participants initial AIS was $A$, during discharge twenty six $(5.9 \%)$ were shifted into $B$, thirty eight $(8.7 \%)$ were shifted into $C$, twenty eight (6.4\%) were shifted into D and unchanged were three hundred forty four (78.7\%). Three hundred and thirty-eight (77.3\%) participants were wheelchair-dependent and forty-nine (11.2\%) were walking at the time of discharge. Most participants had traumatic paraplegia $(278 ; 63.6 \%)$ or traumatic tetraplegia (159; 36.4\%) (Table 2).

Table 3: Relation between AIS and Neurological level during discharge $(n=437)$.

\begin{tabular}{|c|c|c|c|c|c|}
\hline $\begin{array}{c}\text { Neurological level } \\
\text { during discharge }\end{array}$ & A & B & C & D & P value \\
\hline C1-4 & 69 & 4 & 14 & 8 & \\
\hline C5 & 27 & 3 & 7 & 6 & \\
\hline C6 & 9 & 0 & 1 & 2 & \\
\hline C7 & 4 & 0 & 0 & 1 & 0.023 \\
\hline C8 & 2 & 0 & 0 & 0 & \\
\hline T1-6 & 60 & 2 & 0 & 2 & \\
\hline Above T7 & 173 & 17 & 16 & 9 & \\
\hline
\end{tabular}

Distributions of AIS grades by Neurological level are listed in table 3 . AIS grade A were disproportionately represented in the paraplegic group for the full sample about two hundred thirty three (53.31\%) followed by AIS A one seventy three $(39.58 \%)$ mentioning above $\mathrm{T7}$ and sixty (13.72\%) represented T1-6, whereas AIS B seventeen (3.89\%) had above T7 and two $(0.45 \%)$ had T1-6. Either way AIS A sixty nine (15.78\%) found $\mathrm{C} 1-4$ and respectively four (0.91\%) B, fourteen (3.20\%) C and eight (1.83\%) D (Table 3).

Table 4: Relation of diagnosis and AIS during discharge $(n=437)$.

\begin{tabular}{|c|c|c|c|c|}
\hline & \multicolumn{4}{|c|}{ AIS during discharge } \\
\hline Diagnosis & A & B & C & D \\
\hline T/P & 232 & 19 & 16 & 11 \\
\hline T/T & 112 & 7 & 22 & 17 \\
\hline
\end{tabular}

*T/P: Traumatic paraplegia, T/T: Traumatic tetraplegia

* Significance based on chi-square test of significance. $\mathrm{P}=000$.

Out of 437 respondents, two hundred seventy eight $(63.61 \%)$ diagnosis as traumatic para where AIS A 232 (53.08\%), B nineteen (4.34\%), C sixteen (3.66\%), D eleven (2.51\%). One hun- dred fifty eight (36.15) diagnosed as traumatic tetra where $A$ one hundred twelve (25.62\%), B seven (1.60\%), $C$ twenty two (5.03\%), D seventeen (3.89\%).

Table 5: Comparison of initial SCIM and Discharge SCIM with AIS $(n=437)$.

\begin{tabular}{|c|c|c|c|c|}
\hline $\begin{array}{c}\text { Initial AIS } \\
\text { Impairment Class }\end{array}$ & Initial SCIM & $\begin{array}{c}\text { Discharge AIS } \\
\text { Impairment class }\end{array}$ & Discharge SCIM & P value \\
\hline A & $1.86, \pm 9.12$ & A & $11.73, \pm 19.73$ & 1.06 \\
\hline A & $14.73, \pm 6.18$ & B & $57.80, \pm 18.50$ & 0 \\
\hline A & $12.60, \pm 4.71$ & C & $51.50, \pm 22.87$ & 0 \\
\hline A & $16.60, \pm 17.17$ & D & $71.75, \pm 21.80$ & 0.36 \\
\hline
\end{tabular}

Abbreviate: SCIM: Spinal Cord Independence Measure, AIS: American Spinal Injuries Association Impairment Scale. NOTE. Values are mean $\pm S D$.

Patient with ASIA class B and C significantly increase initial SCIM during discharge $(P=0.00)$. There are no other significant relation ought to be seen. The relationship of initial and discharge SCIM with ASIA impairment is shown in (Tab. 4).

\section{DISCUSSION}

Patients admitted with spinal injuries at CRP from June 2014 to June 2017 were selected as the study population and age, gender, educational level, place of habitat, nature of work, and cause of injury were taking into consideration as demographic variables. Male predominance previously reported in both local $[2,16,3]$ and global $[11,10,9]$ studies were also found in this research where $90.2 \%(n=394)$ were male and $9.8 \%(n=43)$ were female. Distribution of age in this study showed more people in their $2^{\text {nd }}$ decade and 3rd decade was vulnerable to spinal cord injury which was different from Scivoletto et al. where the mean age was 50.4 [5] and Marino et al. who found the mean age to be 41 [9]. Injury was evident from the fact that $69.6 \%$ of the respondents were from villages and it was also supported by Rahman et al. [2].

Majority of the participants of this study had traumatic paraplegia (63.6\%) and the principle cause was fall from height (51.3\%) and road traffic accident (28.8\%) which was found to be consistent with other literatures [2, 16, 3, 17]. Bull attack (.5\%) and Diving into shallow water (1.6\%) were the cause of fairly new and interesting phenomenon of spinal cord injury in this research which is recently reported Rahman et al $[2,3]$. Ability of walking is the most crucial question for the severely spinal cord injured patients [7]. 
In our study though the number is not big enough but in comparison of rarity during discharge home AIS A (2.92\%), B (0.67\%), C (2.25\%), D $(5.40 \%)$ are able to walk in a modifiable way and some are able to walk completely (table 2 ). The characteristics (table 2 ) of the participants (437) initial AIS was A and during discharge twenty six (5.9\%) were shifted into $B$, thirty eight (8.7\%) were shifted into C, twenty eight $(6.4 \%)$ were shifted into $D$. Similar result found in other two studies $[18,19]$ where 1-month baseline data reported $4 \%$ to $10 \%$ conversion rate from complete (AIS grade $A$ ) to incomplete injuries (AIS grades B, C, D) also a review [20] of the existing literature reported a conversion rate of $20 \%$ for persons with initial $\left(3^{\text {rd }}-4^{\text {th }}\right)$ week neurologic complete injuries ( $10 \%$ to AIS grade B, $10 \%$ to motor incomplete status).

Another study [9] after completing rehabilitation and during discharge time approximately 74 days $78.3 \%$ remained AIS grade $A$ at discharge from inpatient rehabilitation, whereas $12.1 \%$ shifted to AIS grade B and $9.6 \%$ converted to motor incomplete. Also participants who are initially classified as AIS grade C, 77.2\% improved to AIS grade $D$, whereas $22 \%$ remained AIS grade $C$. (Table 3 ) AIS grade A were disproportionately represented in the paraplegic group for the full sample about two hundred thirty three $(53.31 \%)$ followed by AIS A one seventy three (39.58\%) mentioning above T7 and sixty (13.72\%) represented T1-6. Similar result found in other study [5] where AIS grade A were represent the paraplegia group 53 (18.66\%) and $P=.001$. We believe that Rehabilitation intervention played a positive role in changing the SCIM. In CRP patients are maximum time integrated with functional activities like self-care, mobility, daily activities, respiratory care and also outdoor sports. Strong interdisciplinary team approach played a vital role to fulfillment all these task. There is a high possibility of changing cortical plasticity due to structured and planned extensive therapeutic inventions which may subsequently effect to change SCIM.

In (Table 4) during discharge where paraplegia shows AIS A 232 (53.08\%) unchanged and B nineteen (4.34\%). Traumatic tetraplegia shows $A$ one hundred twelve (25.62\%) unchanged and $B$ seven $(1.60 \%)$. Similar result found in other study
[11] where A 74.4\% unchanged in Paraplegia and 61.3\% unchanged in Tetraplegia. In (Table 5) Patient with AIS class B significantly increase SCIM during discharge $(P=0.00)$ and AIS class $C$ significantly increase SCIM during discharge $(P=0.00)$.

\section{CONCLUSION}

Though neurological recovery and functional outcome is very rare for the complete $\mathrm{SCl}$, but there is a possibility in clinical situation. Sufficient structural integrity for proper signal conduction in the spinal cord after injury and compensatory plastic changes in the cortex, both may necessary for neurological and functional improvements. Proper physical and occupational therapeutic intervention may play a vital role in developing cortical plasticity. So, further large scale studies would be better to explore the variables and contributing factors that may help in neurological recovery and functional outcome of spinal cord injury patients.

\section{ACKNOWLEDGEMENT}

Authors thank medical services of CRP for their necessary help and cooperation

Funding: It was a self-funded study.

\section{Conflicts of interest: None}

\section{REFERENCES}

[1]. Quadir MM, Sen K, Sultana MR, Ahmed MS, Taoheed F, Andalib A, et al. Demography, Diagnosis and Complications of Spinal Cord Injury Patients in a Rehabilitation Center of Bangladesh. Int $J$ Neurorehabilitation. 2017;4(1):e244

[2]. Rahman A, Ahmed S, Sultana R, Taoheed F, Andalib A, Arafat SY. Epidemiology of Spinal Cord Injury in Bangladesh: A Five Year Observation from a Rehabilitation Center. J Spine. 2017;6(2):1000367.

[3]. Andalib A, Arafat SMY. Does It Really Matters: Bull Attack as a Cause of Spinal Cord Injury in Bangladesh? South East Asia J Med Sci. 2017;1(1):3.

[4]. Razzak A, Helal SU, Nuri R. Life Expectancy of Persons with Spinal Cord Injury (SCl) Treated in a Rehabilitation Centre at Dhaka, Bangladesh. 2011:22(1):114-123.

[5]. Scivoletto G, Morganti B, Molinari M. Neurologic recovery of spinal cord injury patients in Italy. Archives of Physical Medicine and Rehabilitation. 2004;85(3):485-489.

[6]. Rossignol S, Schwab M, Schwartz M, Fehlings M. Spinal Cord Injury: Time to Move?. Journal of Neuroscience. 2007;27(44):11782-11792.

[7]. Scivoletto G, Tamburella F, Laurenza L, Torre M, Molinari M. Who is going to walk? A review of the 
factors influencing walking recovery after spinal cord injury. Frontiers in Human Neuroscience. 2014;8.

[8]. Catz A, Thaleisnik M, Fishel B, et al. Recovery of neurologic function after spinal cord injury in Israel. Spine 2002;27:1733-5.

[9]. Marino R, Burns S, Graves D, Leiby B, Kirshblum S, Lammertse D. Upper- and Lower-Extremity Motor Recovery After Traumatic Cervical Spinal Cord Injury: An Update From the National Spinal Cord Injury Database. Archives of Physical Medicine and Rehabilitation. 2011;92(3):369-375.

[10]. Marino RJ, Ditunno JF Jr, Donovan WH, Maynard F Jr. Neurologic recovery after traumatic spinal cord injury: data from the Model Spinal Cord Injury Systems. Arch Phys Med Rehabil 1999;80:1391-6.

[11]. Kirshblum S, Botticello A, Lammertse D, Marino R, Chiodo A, Jha A. The Impact of Sacral Sensory Sparing in Motor Complete Spinal Cord Injury. Archives of Physical Medicine and Rehabilitation. 2011;92(3):376-383.

[12]. Brown PJ, Marino RJ, Herbison GJ, Ditunno JFJ. The 72-hour examination as a predictor of recovery in motor complete quadriplegia. Arch Phys Med Rehabil 1991;72:546-8.

[13]. Maynard FM Jr, Bracken MB, Creasey G, et al. International Standards for Neurological and Functional Classification of Spinal Cord Injury. American Spinal Injury Association. Spinal Cord 1997;35:266-74.

[14]. Catz A, Itzkovich M, Agranov E, Ring H, Tamir A. SCIM - spinal cord independence measure: a new disability scale for patients with spinal cord lesions. Spinal Cord. 1997;35(12):850-856.
[15]. Centre for Rehabilitation of the Paralyzed (2014) Annual Report: 2013-2014, CRP Printing Press: Bangladesh.

[16]. Hoque MF, Grangeon C, Reed K (1999) Spinal cord lesions in Bangladesh: An epidemiological study 1994-1995. Spinal Cord 37: 858-861.

[17]. Hoque M, Hasan Z, Razzak A, Helal SU. Cervical spinal cord injury due to fall while carrying heavy load on head: a problem in Bangladesh. Spinal Cord. 2011;50(4):275-277.

[18]. Waters R, Adkins R, Yakura J, Sie I. Motor and sensory recovery following complete tetraplegia. Archives of Physical Medicine and Rehabilitation. 1993;74:242-7.

[19]. Waters R, Adkins R, Yakura J, Sie I. Motor and sensory recovery following incomplete tetraplegia. Archives of Physical Medicine and Rehabilitation. 1994;75(3):306-311.

[20]. Fawcett J, Curt A, Steeves J, Coleman W, Tuszynski M, Lammertse D et al. Guidelines for the conduct of clinical trials for spinal cord injury as developed by the ICCP panel: spontaneous recovery after spinal cord injury and statistical power needed for therapeutic clinical trials. Spinal Cord. 2006;45(3):190-205.

\footnotetext{
How to cite this article:

Kamrunnaher, Sayeed Uddin Helal, Palash Chandra Saha, Farzana Taoheed, S.M. Yasir Arafat, Md. Akhlasur Rahman, Md. Shahoriar Ahmed. NEUROLOGICAL RECOVERY AND FUNCTIONAL OUTCOME OF COMPLETE TRAUMATIC SPINAL CORD INJURY PATIENTS: AN OBSERVATION FROM BANGLADESH. Int J Physiother Res 2018;6(2):2648-2653. DOI: 10.16965/ ijpr.2018.106
} 